\title{
Aspectos técnico-ambientais da produção orgânica na região citrícola do Vale do Rio Caí, RS
}

\author{
Technical and environment aspects of the organic production on citric region of \\ Caí Valley, in the state of Rio Grande do Sul, Brazil
}

\author{
Nestor Valtir Panzenhagen ${ }^{\text {I }}$ Otto Carlos KollerII Paulo Dabdab Vaquil ${ }^{\text {III }}$ \\ Paulo Vitor Dutra de Souza ${ }^{\text {II }}$ Fábio Kessler Dal Soglio ${ }^{\mathrm{IV}}$
}

\section{RESUMO}

Há uma preocupação crescente sobre a necessidade de produção e consumo de alimentos mais saudáveis, sem uso de agrotóxicos nem fertilizantes sintéticoindustriais. Neste contexto se insere a prática da agricultura orgânica, que, contudo, apresenta resultados ainda pouco avaliados nos meios acadêmicos e científicos. Assim, pretendeuse nesta pesquisa diagnosticar aspectos técnico-ambientais da produção orgânica na região citrícola do Vale do Rio Caí, no Rio Grande do Sul. Inicialmente, foram selecionadas propriedades de oito agricultores familiares, todas já convertidas ao sistema orgânico de produção, sendo aplicadas entrevistas semi-estruturadas. Os produtores mostram-se satisfeitos com o sistema orgânico de produção e revelam bom conhecimento sobre o ambiente, plantas, solos e processos agroecológicos, adquiridos através da participação em eventos técnicos e em reuniões da Cooperativa Ecocitrus. A constante troca de experiências entre esses agricultores tem melhorado sua qualificação técnica, além de melhor conscientizá-los nos aspectos políticos, econômicos e sociais.

Palavras-chave: citros, fruticultura, sistema de produção, produção orgânica.

\section{ABSTRACT}

There's a growing concern about the need for production and consumption of healthier food, without pesticides and chemical fertilizers. The practice of organic agriculture appears in this context, but still shows little assessed results in the academic and scientific context. Thus, this research is aimed at the diagnoses of organic production of citrus in the region of Caí Valley, in southern Brazil. Initially eight producers were selected, all already converted to the organic production system. To carry out the research, semi-structured

\begin{abstract}
surveys were applied, seeking the diagnoses of technical and environmental aspects. The organic producers have shown to be satisfied with the organic production system. Moreover, show good knowledge about the environment, plants, soil and agrobiological processes, which is possible technical events and meetings, between these of the Ecocitrus cooperative. The constant sharing of experiences among organic producers has improved their technical qualification, besides providing better awareness in the political, economic and social aspects.
\end{abstract}

Key words: citrus, fruit production, production system, organic production.

\section{INTRODUÇÃO}

O Brasil é o maior produtor mundial de frutas cítricas, com uma produção que, segundo a FAO (2004), ultrapassa 23 milhões de toneladas, numa área de 1 milhão de hectares cultivados, representando mais de 25\% da produção mundial.

No Rio Grande do Sul, a citricultura é a atividade frutícola que ocupa a maior área, totalizando 42.015ha. As culturas da laranjeira, da tangerineira e do limoeiro juntos geraram aproximadamente 506 mil toneladas de frutas no ano de 2005 (IBGE, 2006). As frutas cítricas são destinadas preponderantemente ao consumo de mesa, sendo suas culturas fundamentadas em pequenos pomares, com área média de 2 a 3 hectares, e de exploração familiar, exercendo importante papel na

IEscola Agrotécnica Federal de Sombrio, SC. Estrada Geral, s/n, Vila Nova, 88965-000, Santa Rosa do Sul, SC, Brasil. E-mail: nestorpanzen@yahoo.es. Autor para correspondência.

IIDepartamento de Horticultura e Silvicultura, Universidade Federal do Rio Grande do Sul (UFRGS), Porto Alegre, RS, Brasil.

IIIDesenvolvimento Rural, UFRGS, Porto Alegre, RS, Brasil.

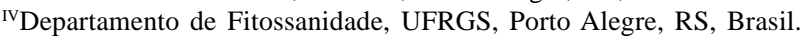


geração de empregos e na fixação do homem no campo (BONINE \& JOÃO, 2002).

$\mathrm{O}$ uso de inseticidas, acaricidas, fungicidas e outros métodos de controle químico desequilibram e poluem cada vez mais o ambiente (PRIMAVESI, 1980). Segundo GLIESSMAN (2001), nas unidades agrícolas, a mudança para a mecanização pesada e o elevado uso de insumos sintético-industriais, derivados de combustíveis fósseis, promoveram perdas da matéria orgânica, a lixiviação de nutrientes, a degradação e o aumento da erosão do solo. De modo geral, também as pragas desenvolveram resistência aos agrotóxicos e esses contaminaram tanto os ambientes agrícolas quanto os ecossistemas naturais, causando problemas de saúde para produtores e assalariados agrícolas e destruindo populações de insetos e microorganismos benéficos.

Por outro lado, diversos são os fatores que estão encorajando os produtores a substituir o cultivo convencional por práticas sustentáveis. Entre eles citam-se o desenvolvimento de novas práticas que são vistas como opções viáveis, o aumento da consciência ambiental entre consumidores e produtores, a abertura de novos e mais consistentes mercados para produtos agrícolas cultivados e processados de forma alternativa (GLIESSMAN, 2001).

Segundo a Instrução Normativa ํo 007, de 17 de maio de 1999, do Ministério da Agricultura e do Abastecimento, considera-se sistema orgânico de produção agropecuária e industrial todo aquele em que se adotam tecnologias que otimizem o uso de recursos naturais e sócio-econômicos, respeitando a integridade cultural e tendo por objetivo a auto-sustentação no tempo e no espaço, a maximização dos benefícios sociais, a minimização da dependência de energias nãorenováveis e a eliminação do emprego de agrotóxicos e outros insumos artificiais tóxicos, organismos geneticamente modificados ou radiações ionizantes em qualquer fase do processo de produção, armazenamento e de consumo, e entre os mesmos, privilegiando a preservação da saúde ambiental e humana, assegurando a transparência em todos os estágios da produção e da transformação.

Assim, a presente pesquisa visou ao estudo da produção orgânica na região do Vale do Rio Caí, no Rio Grande do Sul, levando em consideração os aspectos técnico-ambientais.

\section{MATERIAL E MÉTODOS}

Para a produção vegetal de culturas perenes, o Ministério da Agricultura e do Abastecimento, de acordo com a Instrução Normativa n⿳ํㅜ 007, de 17 de maio de 1999, exige um período mínimo de 18 meses de manejo orgânico para que a unidade de produção seja efetivamente convertida, possibilitando que a colheita subseqüente seja certificada.

Assim, em um universo de 46 agricultores associados da Cooperativa dos Citricultores Ecológicos do Vale do Rio Caí, RS (Ecocitrus), foram selecionadas aleatoriamente as propriedades de oito agricultores, todos já convertidas ao sistema orgânico de produção. Destas, sete situam-se no município de Montenegro/RS e uma em Harmonia/RS. Com cada agricultor, foram realizadas entrevistas semiestruturadas, durante o segundo semestre de 2003, visando ao diagnóstico dos aspectos técnicoambientais. O referido instrumento foi construído buscando-se obter o maior número de informações que pudessem servir de base para a pesquisa, sempre levando em consideração a realidade local dos agricultores.

A caracterização dos aspectos técnicos envolvidos na produção de citros constou de técnicas adotadas para preparo dos solos na implantação das culturas; o itinerário técnico (manejo do solo, rotação de culturas intercalares de inverno e de verão, controle de plantas espontâneas, adubação, manejo dos insetos e tratamentos fitossanitários, poda, raleio de frutos e colheita); os equipamentos utilizados no manejo geral da propriedade e as melhorias projetadas.

Os resultados referentes à análise dos solos foram obtidos conforme metodologia descrita por TEDESCO et al. (1995), a partir de coletas de solos realizadas durante o mês de fevereiro de 2004, feitas nas entrelinhas das plantas de citros, de 0 a $20 \mathrm{~cm}$ de profundidade.

Também em relação aos demais cultivos foi realizado um levantamento das principais espécies relacionadas às respectivas áreas cultivadas, bem como do itinerário técnico dos mesmos.

\section{RESULTADOS E DISCUSSÃO}

O tempo médio de conversão ao sistema orgânico de cultivo situou-se em dez anos e seis meses, com uma amplitude de 9 a 14 anos.

A área total das propriedades variou de 3,1 a 87,0ha (Tabela 1), sendo a grande maioria constituída com menos de 20,0ha. Essas informações confirmam os dados censitários da região, que indicam que a mesma é constituída essencialmente por pequenos estabelecimentos agrícolas, conforme levantamentos efetuados por BONINE \& JOÃO (2002).

A fruticultura destaca-se como principal atividade, ocupando praticamente $61 \%$ da área total 
Tabela 1 - Principais usos e respectivas áreas (em ha) das unidades produtivas orgânicas do Vale do Rio Caí, RS.

\begin{tabular}{|c|c|c|c|c|c|c|c|}
\hline \multirow{2}{*}{$\begin{array}{l}\text { Unidade de } \\
\text { produção agrícola }\end{array}$} & \multicolumn{6}{|c|}{ Distribuição da área (em ha) na propriedade } & \multirow{2}{*}{$\begin{array}{c}\text { Área total da } \\
\text { propriedade }\end{array}$} \\
\hline & Benfeitorias & Pastagem & Mata nativa & Reflorestamento & Plantas anuais & Fruticultura & \\
\hline 1 & 0,05 & 0,05 & 0,00 & 1,10 & 0,20 & 11,60 & 13,00 \\
\hline 2 & 0,05 & 0,15 & 2,30 & 2,10 & 1,10 & 9,10 & 14,80 \\
\hline 3 & 0,09 & 3,21 & 6,30 & 0,00 & 1,50 & 4,90 & 16,00 \\
\hline 4 & 0,06 & 2,70 & 12,74 & 1,50 & 1,00 & 16,00 & 34,00 \\
\hline 5 & 0,04 & 0,06 & 0,20 & 0,10 & 0,00 & 2,70 & 3,10 \\
\hline 6 & 0,04 & 10,66 & 14,30 & 1,00 & 2,00 & 59,00 & 87,00 \\
\hline 7 & 0,03 & 0,77 & 0,20 & 0,00 & 0,00 & 4,80 & 5,80 \\
\hline 8 & 0,12 & 2,48 & 3,10 & 2,50 & 1,60 & 9,20 & 19,00 \\
\hline Média & 0,07 & 2,51 & 4,88 & 1,04 & 0,93 & 14,66 & 24,09 \\
\hline$\%$ total & 0,29 & 10,41 & 20,26 & 4,32 & 3,86 & 60,86 & 100,00 \\
\hline
\end{tabular}

das propriedades, preponderantemente de citros. A área florestal média das propriedades, que inclui a mata nativa remanescente e as áreas reflorestadas, ocupa praticamente $25 \%$ das unidades produtivas e constitui um indicativo de preocupação dos produtores com a preservação do ambiente. Se, ainda, forem somadas as áreas destinadas ao cultivo de plantas frutíferas, verifica-se que mais de $85 \%$ das áreas das unidades produtivas são constituídas, preponderantemente, de espécies arbóreas (Tabela 1).

Em todas as unidades produtivas há uma predominância no cultivo de tangerineiras, representando praticamente $85 \%$ da área cultivada com citros e do número de plantas (Tabela 2). Dentre as tangerineiras, destaca-se o cultivo da "Montenegrina", com 60,3\%, seguida da "Murcote”, com 17,1\%. Em menor proporção, situa-se a cultivar "Pareci”, com 8,3\%, seguida da "Ponkan”, com 6,8\%, e da “Caí”, com $6,5 \%$. Praticamente todas as unidades produtivas cultivam, em maior ou menor escala, essas cinco cultivares. Esses plantios de citros concentram-se em idades de 11 aos 15 anos, representando praticamente um terço dos plantios. Entretanto, cerca de $84 \%$ deles apresentam idade de até 20 anos, o que permite caracterizá-los como sendo relativamente jovens.

O porta-enxerto Poncirus trifoliata é usado de forma generalizada, representando mais de $95 \%$ dos casos. Apenas 3,1\% dos porta-enxertos são constituídos pelo limoeiro "Cravo” e 1,7\% pela laranjeira “Caipira” ou “Comum”. De acordo com KOLLER (1994) e SCHÄFER (2000), a pouca diversificação de portaenxertos de citros aumenta os riscos do comprometimento de uma citricultura estabelecida preponderantemente sobre um único porta-enxerto, em conseqüência do eventual surgimento ou introdução de pragas que possam afetar esse porta-enxerto.

Na implantação de plantios de citros, todos os agricultores adotam a prática de lavração de toda a área, momentos antes do plantio das mudas. A diversidade de opiniões surge quanto à aplicação ou não de biofertilizante líquido e/ou composto orgânico antes da lavração. Assim, há basicamente a

Tabela 2 - Percentagens de área e número de laranjeiras, limoeiros e limeiras, e tangerineiras cultivados nas unidades de produção agrícola orgânica do Vale do Rio Caí, RS.

\begin{tabular}{|c|c|c|c|c|c|c|}
\hline \multirow{2}{*}{ Unidade de produção agrícola } & \multicolumn{2}{|c|}{ Laranjeiras } & \multicolumn{2}{|c|}{ Limoeiros e limeiras } & \multicolumn{2}{|c|}{ Tangerineiras } \\
\hline & Área & № de plantas & Área & № de plantas & Área & № de plantas \\
\hline 1 & 6,03 & 5,61 & 0,00 & 0,00 & 93,97 & 94,39 \\
\hline 2 & 4,95 & 2,75 & 0,00 & 0,00 & 95,05 & 97,25 \\
\hline 3 & 8,33 & 7,51 & 0,00 & 0,00 & 91,67 & 92,49 \\
\hline 4 & 30,00 & 26,76 & 3,13 & 3,28 & 66,88 & 69,96 \\
\hline 5 & 24,07 & 24,41 & 0,00 & 0,00 & 75,93 & 75,59 \\
\hline 6 & 5,50 & 4,79 & 10,99 & 11,06 & 83,51 & 84,15 \\
\hline 7 & 25,00 & 23,88 & 0,00 & 0,00 & 75,00 & 76,12 \\
\hline 8 & 4,88 & 4,56 & 0,00 & 0,00 & 95,12 & 95,44 \\
\hline Média & 13,60 & 12,53 & 1,76 & 1,79 & 84,64 & 85,67 \\
\hline
\end{tabular}

Ciência Rural, v.38, n.1, jan-fev, 2008. 
identificação de dois grupos de opiniões: $38 \%$ dos entrevistados preferem espalhar compostos orgânicos e/ou biofertilizantes líquidos em toda a área, para serem incorporados ao solo pela lavração, e 63\% preferem a lavração total da área, sem incorporação de adubos orgânicos. Destes, 60\% optam pelo uso de composto orgânico na cova de plantio. Em todas as situações, os agricultores fazem aplicações de composto orgânico e biofertilizante líquido em cobertura, isto é, após a instalação dos pomares, o que, além de promover melhor desenvolvimento das plantas cítricas, possibilita o plantio de espécies anuais intercalares, como, por exemplo, milho, mandioca e feijão, principalmente nos anos iniciais de desenvolvimento das plantas cítricas.

Em relação ao manejo do solo nas entrelinhas dos plantios de citros, constata-se que, durante o período de outono e inverno, em 99\% dos pomares, as entrelinhas apresentam-se cobertas com vegetação nativa ou espontânea. Já no período da primavera e verão, esse índice apresenta uma pequena queda, passando para $90 \%$, em virtude de cultivos intercalares com espécies de plantas anuais. A manutenção da cobertura verde do solo tem favorecido a intensificação da diversidade de espécies vegetais intercalares aos citros, favorecendo o controle da erosão, a reciclagem de nutrientes e o maior equilíbrio geral. De acordo com ALTIERI (1991), o aumento da diversidade de espécies vegetais normalmente correlaciona-se positivamente com a diversidade de espécies de inimigos naturais de pragas agrícolas, possivelmente devido à maior diversidade de habitats e à maior disponibilidade de recursos alimentares, distribuídos no espaço e no tempo.

As práticas adotadas visando ao controle de plantas espontâneas igualmente sofreram mudanças após a conversão ao sistema orgânico de produção, mantendo-se atualmente. Assim, os herbicidas e as capinas foram substituídos pelas roçadas e tombamento (acamamento) da vegetação. Destas, a roçada é a principal forma utilizada para o controle. Verifica-se que $75 \%$ dos agricultores adotam-na como prática única no controle de plantas espontâneas. Os restantes $25 \%$ utilizam-se da prática do tombamento da vegetação nas entrelinhas e de roçadas manuais nas linhas de cultivo.

De acordo com os padrões da Comissão de Fertilidade do Solo - RS e SC (1994), verifica-se, na tabela 3 , que o $\mathrm{pH}$ dos solos é invariavelmente alto (acima de 6,0), apesar da ausência da prática da calagem nessas áreas. Este resultado é devido, provavelmente, ao continuado uso do biofertilizante líquido como fonte de adubação dos pomares, pois este contém, em sua composição, considerável quantidade de cinzas, com poder alcalinizante. Os teores de matéria orgânica do solo variaram de 1,1 a 3,4\%, com uma média de $2,4 \%$. Os teores de fósforo disponíveis são altos em todas as análises efetuadas. Há disponibilidade de média a alta de potássio e de cálcio nos solos. Já os teores de magnésio variaram desde a baixa até a alta disponibilidade. Esta variabilidade em relação à disponibilidade de nutrientes em cada propriedade está provavelmente relacionada ao $\mathrm{pH}$ dos solos, às distintas características físicas, químicas e biológicas dos solos e às diferentes fontes, constituições, quantidades e periodicidade de aplicação de adubos orgânicos em cada unidade de produção agrícola.

Em relação aos problemas fitossanitários, existe grande preocupação em controlar principalmente a pinta preta, causada pelo fungo Guignardia citricarpa, devido às perdas que esta doença causa na produção de frutos, estimadas em $11 \%$. Ainda com relação aos principais problemas fitossanitários, destacam-se os estragos provocados pelas moscasdas-frutas (Anastrepha fraterculus), referida por todos

Tabela 3 - Teores de argila, pH, matéria orgânica (MO) e de macronutrientes do solo em pomares orgânicos de citros do Vale do Rio Caí, RS.

\begin{tabular}{|c|c|c|c|c|c|c|c|c|}
\hline \multirow{2}{*}{$\begin{array}{l}\text { Unidade de } \\
\text { produção agrícola }\end{array}$} & \multirow{2}{*}{$\begin{array}{l}\text { Argila } \\
\text { (\%) }\end{array}$} & \multirow{2}{*}{$\begin{array}{l}\text { PH em } \\
\text { água }\end{array}$} & \multirow{2}{*}{ MO (\%) } & \multicolumn{5}{|c|}{ Macronutrientes } \\
\hline & & & & Fósforo & Potássio & Cálcio & Magnésio & Enxofre \\
\hline & & & & $\mathrm{mg} \mathrm{dm}{ }^{-3}$ & $\mathrm{mg} \mathrm{dm}{ }^{-3}$ & $\mathrm{cmol} \mathrm{dm}^{-3}$ & $\mathrm{cmol} \mathrm{dm}^{-3}$ & $\mathrm{mg} \mathrm{dm} \mathrm{m}^{-3}$ \\
\hline 1 & 11 & 6,9 & 1,8 & 76 & 61 & 4,2 & 0,5 & 6,0 \\
\hline 2 & 36 & 7,1 & 3,4 & 18 & 108 & 14,5 & 2,7 & 7,0 \\
\hline 3 & 08 & 7,1 & 1,1 & 46 & 64 & 3,4 & 0,4 & 7,2 \\
\hline 4 & 26 & 7,1 & 2,7 & 100 & 105 & 9,5 & 1,1 & 7,5 \\
\hline 5 & 13 & 7,1 & 2,7 & 67 & 69 & 6,3 & 0,5 & 5,7 \\
\hline 6 & 13 & 6,3 & 1,7 & 32 & 66 & 2,9 & 0,7 & 6,2 \\
\hline 7 & 18 & 7,1 & 1,9 & 29 & 126 & 6,4 & 0,9 & 7,5 \\
\hline 8 & 40 & 6,8 & 3,8 & 20 & 71 & 11,7 & 2,5 & 7,2 \\
\hline Média & 20,6 & 6,9 & 2,4 & 48 & 84 & 7,4 & 1,2 & 6,8 \\
\hline
\end{tabular}

Ciência Rural, v.38, n.1, jan-fev, 2008. 
os citricultores, com estimativas de danos de até $20 \%$ do total da produção. A média de perdas, no entanto, é estimada em aproximadamente 6,9\%. Aproximadamente $88 \%$ dos produtores fazem uso regular da calda bordalesa e $63 \%$ fazem o mesmo com a calda sulfocálcica. A aplicação da calda bordalesa visa basicamente a controlar o ataque da verrugose, causada pelo fungo Elsinoe fawcetti, da pinta preta e do cancro cítrico, causado pela bactéria Xanthomonas citri. Embora as perdas causadas pelas moscas-dasfrutas possam ser consideradas significativas, pouco é feito para controlar essa praga. Algumas experiências e/ou práticas isoladas de controle estão sendo aplicadas por poucos produtores, como o uso de pulverizações com soluções contendo urina de gado, esterco líquido de suínos ou soro de leite, supondo-se que possam ter ação repelente às moscas.

Em relação à poda, atualmente $63 \%$ dos entrevistados cortam anualmente, pela base, três a quatro ramos internos de cada tangerineira, utilizando serrote e tesoura de poda, enquanto $25 \%$ fazem essa prática a cada dois anos. O raleio de frutos nas tangerineiras é uma prática utilizada por todos os citricultores e não ocorrem muitas diferenças na intensidade de frutos raleados, nem na época de realização, quando se leva em consideração uma determinada variedade. Assim, tanto na tangerineira “Caí”, quanto na “Montenegrina”, retiram-se aproximadamente dois terços dos frutos de plantas muito carregadas. Aépoca de raleio da "Montenegrina" concentra-se no mês de março, enquanto que o raleio de frutos da "Caí” é antecipada para fevereiro.

Além da fruticultura, todos os produtores desenvolvem outras atividades agrícolas, relacionadas com o cultivo de espécies de ciclo anual. Destaca-se o milho, cultivado por $88 \%$ dos produtores, seguido pela mandioca, com $63 \%$, feijão, produzido por $50 \%$ dos mesmos, e do cultivo de espécies olerícolas, atividade desenvolvida por 38\% dos entrevistados. Visando à diminuição da concorrência de plantas espontâneas, alguns produtores primeiramente aplicam biofertilizante líquido. Isto estimula o nascimento de plantas espontâneas (inços), que, alguns dias mais tarde, são incorporadas ao solo com uma lavração, seguida do plantio da cultura intercalar, prática realizada apenas em pomares novos.

Do total, 63\% das propriedades apresentam algum sistema agroflorestal. No entanto, são áreas muito incipientes, que variam de 0,2 a 2,0ha, com uma média aproximada de 1,0ha, referente basicamente ao plantio ou desenvolvimento espontâneo de espécies silvestres no interior dos pomares. Outros 25\% dos citricultores pretendem futuramente implantar sistemas agroflorestais nas suas propriedades. As espécies atualmente cultivadas ou selecionadas no interior dos pomares são principalmente o açoita-cavalo (Lueha divaricata), a canafístula (Senna multijuga), o cedro (Cedrela odarata), o cinamomo (Melia azedarach L.), o ipê (Tabebuia chrysotricha) e o angico (Anadenanthera colubrina). Em relação ao manejo que será dado às árvores florestais no interior das plantas de citros, há uma conscientização praticamente generalizada em podá-las periodicamente, com corte dos ramos mais próximos do solo, visando, assim, à formação de copas mais altas, para diminuir a competição por espaço e luz em relação aos citros. Cerca de $86 \%$ dos produtores acreditam que a implantação de agroflorestas diminuirá a produtividade dos citros, mas citam algumas compensações. Entre elas, 86\% entendem que haverá diminuição das lesões de pinta preta e da queimadura solar da casca dos frutos. Outras compensações citadas são a reciclagem de nutrientes minerais promovida pelas espécies florestais, a conservação da umidade do solo, a presença de maior diversidade nas áreas citrícolas e a produção de lenha ou madeira.

Em termos gerais, os agricultores que se dedicam ao sistema orgânico de produção revelam bom conhecimento sobre o ambiente, plantas, solos e processos agroecológicos, aspectos políticos, econômicos e sociais, adquiridos através da participação em cursos, palestras, congressos, dias de campo, treinamentos e através das reuniões e assembléias da Cooperativa ECOCITRUS. A constante troca de experiências entre os agricultores orgânicos tem contribuído na melhoria da qualificação técnica dos mesmos, além de melhor conscientizá-los nos aspectos políticos, econômicos e sociais. A participação na Cooperativa tem proporcionado melhor organização dos mesmos, contribuindo na viabilização da produção orgânica, inclusive com vantagens econômico-comerciais, pela obtenção de insumos orgânicos, venda da produção e estímulo ao beneficiamento da produção, visando a agregar renda à propriedade.

\section{CONCLUSÕES}

A citricultura é a principal atividade das unidades de produção agrícola do Vale do Caí, com predominância no cultivo de tangerineiras, principalmente da cultivar "Montenegrina”. O cultivo é diversificado, com a presença de espécies anuais em todas as propriedades.

No sistema orgânico de produção, a vegetação espontânea dos pomares de citros é

Ciência Rural, v.38, n.1, jan-fev, 2008. 
controlada com uma ou duas roçadas anuais ou pelo tombamento nas entrelinhas. Os cultivos agroflorestais são ainda incipientes e caracterizam-se por uso de espécies arbóreas intercalares para sombreamento e se apresentam como alternativa promissora.

A produção orgânica de alimentos resultou em benefícios concretos para as populações locais, como redução da contaminação ambiental, em níveis até por vezes desprezíveis, contribuindo conseqüentemente na recuperação e melhoria da qualidade dos recursos naturais e na colheita de produtos sem contaminações por agroquímicos. Além disso, é preciso mencionar que a produção orgânica também proporciona satisfação pessoal ao agricultor em produzir e oferecer ao mercado consumidor produtos de melhor qualidade.

\section{AGRADECIMENTOS}

A presente pesquisa foi viabilizada graças ao empenho dos pesquisadores envolvidos no projeto, bem como a colaboração dos agricultores entrevistados. Cabe também ressaltar o apoio financeiro do CNPq, que muito contribuiu na execução do referido projeto de pesquisa.

\section{REFERÊNCIAS}

ALTIERI, M.A. How best can we use biodiversity in agroecosystem. Outlook on Agriculture, Wallingford, v.20, n.1, p.15-23, 1991.
BONINE, D.P.; JOÃO, P.L. Estudo da cadeia produtiva dos citros no Vale do Caí/RS. Informativo da EMATER/RS: Série realidade rural, Porto Alegre, v.29, 74p, 2002.

COMISSÃO DE FERTILIDADE DO SOLO - RS e SC. 1995. Recomendações de adubação e de calagem para os estados do Rio Grande do Sul e de Santa Catarina. 3.ed. Passo Fundo: SBCS - Núcleo Regional Sul, 1994. p.1-224.

FAO - Food and Agriculture Organization of the United Nations. Contém dados sobre a produção agrícola, incluindo a de laranjas no Brasil. Acesso em: 20 jul 2004. Disponível online em: <http://www.fao.org/>.

GLiessman, S.R. Agroecologia - Processos ecológicos em agricultura sustentável. Porto Alegre: UFRGS, 2001. 653p.

IBGE. Levantamento sistemático da produção agrícola: 1996. Acesso em: 02 mar. 2007. On line. Disponível em: $<$ http://www.ibge.org.br>

KOLLER, O.C. Citricultura: laranja, limão e tangerina. Porto Alegre: Rígel, 1994. 446p.

PRIMAVESI, A. Manejo ecológico do solo. São Paulo: Nobel, 1980. 541p.

SCHÄFER, G. Caracterização molecular, diagnóstico e avaliação de porta-enxertos na citricultura gaúcha. 2000. 81f. Dissertação (Mestrado em Fitotecnia) - Programa de Pósgraduação em Fitotecnia, Universidade Federal do Rio Grande do Sul.

TEDESCO, M.J. et al. Análise de solo, plantas e outros materiais. 2.ed. Porto Alegre: Departamento de Solos/ UFRGS, 1995. 174p. (Boletim Técnico, 5). 